\title{
Tawny owl Strix aluco as a potential transmitter of Enterobacteriaceae epidemiologically relevant for forest service workers, nature protection service and ornithologists
}

\author{
Grzegorz Grzywaczewski ${ }^{1}$, Danuta Kowalczyk-Pecka', Szymon Cios', Wiktor Bojar², \\ Andrzej Junkuszew ${ }^{2}$, Hubert Bojar ${ }^{3}$, Marcin Kolejko ${ }^{4}$ \\ ${ }^{1}$ Department of Zoology, Animal Ecology and Wildlife Management, University of Life Science, Lublin, Poland \\ ${ }^{2}$ Department of Small Ruminants Breeding and Agriculture Advisory, University of Life Science, Lublin, Poland \\ ${ }^{3}$ Independent Laboratory for Cell Metabolism, Institute of Rural Health, Lublin, Poland \\ ${ }^{4}$ Department of Landscape Ecology and Nature Conservation, University of Life Science in Lublin, Poland
}

Grzywaczewski G, Kowalczyk-Pecka D, Cios Sz, Bojar W, Junkuszew A, Bojar H. Tawny owl Strix aluco as a potential transmitter of Enterobacteriaceae epidemiologically relevant for forest service workers, nature protection service and ornithologists. Ann Agric Environ Med. 2017; 24(1): 62-65. doi: $10.5604 / 12321966.1230732$

\begin{abstract}
I Abstract
Established taxa within the Enterobacteriaceae wereisolated from cloacal swabs of Strix aluco chicks in nest boxes located at five research sites. ChromID ESBL medium (bioMerieux) was used to select a pool of Enterobacteriaceae strains producing extendedspectrum beta-lactamases. Drug sensitivity of the chosen strains was determined from the full pool of Enterobacteriaceae to 6 chemotherapeutics of different mechanisms of action. The study evaluated the sensitivity of ESBL-synthesizing isolates to substances belonging to penicillins, cephalosporins, cephamycins, clavams, carbapenems and monobactams. Analysis of the results indicated a potential role of Strix aluco in the dissemination of epidemiologically-relevant Enterobacteriaceae, and, importantly, pose health risks to forest service workers, nature protection service and ornithologists. The results can also serve as the basis for further environmental studies.
\end{abstract}

I Key words

tawny owl, Strix aluco, Enterobacteriaceae

\section{INTRODUCTION}

The tawny owl Strix aluco is the most common and numerous owl species in Europe [1] and in Poland [2]. The species is well adapted to inhabit a wide range of landscapes, i.e. woodland, rural and urban environments. Most commonly, tawny owls are a cavity nesting species that reside in tree cavities of 1.5 $3 \mathrm{~m}$ depth, as well as in deep hollows in old trees. Their habitat preferences also include man-made structures, crevices in cliffs, under tree trunks, nest baskets and boxes, and even nests made by other birds of prey and crows. Tawny owls are common mostly in forests where they reach the highest population density [3].

In virtue of its abundant occurrence and nesting predominantly in forest tree holes, forest workers, including both foresters and forest service workers, prove to be the most exposed to contact with this bird species. Employees of the nature protection service (Regional Directorates for Environmental Protection, national parks, landscape parks) professionally engaged in species conservation pursuant to the Act on Nature Protection, also come into contact with tawny owls. Workers of the nature protection service provide care to sick and injured animals or flightless chicks. Another group of people with direct occupational exposure to this bird species comprises ornithologists studying the biology, ecology and ringing of this species.

Address for correspondence: Wiktor Bojar, Department of Small Ruminants Breeding and Agriculture Advisory. University of Life Science in Lublin, Poland E-mail: w.bojar@o2.pl

Received: 13 January 2014; accepted: 11 December 2014; first published on January 2017
The current reviews on biological occupational risk among, e.g. forest workers, have focused primarily on infection with borreliosis, rabies, tularaemia, tick-borne encephalitis and meningitis, when ticks are considered the major immediate source of human infection, as well as vectors of biological agents such as bacteria and viruses. However, no information is available on the role of the birds as transmitters of biological agents in forests, and potential zoonotic threat to forest workers health $[4,5,6]$.

The occurrence and development of bacterial resistance to chemotherapeutic agents limit the ability to combat serious infections produced by the microorganisms. At present, some bacteria species have acquired resistance to all accessible antibiotics. Widespread overuse and misuse of antibiotics have created an increasing incidence rate and transmission of multidrug resistance, a national and global problem for the current medical sciences $[7,8,9]$. The strains synthesizing beta-lactamases representing different bacterial taxa are of special clinical and epidemiological importance $[10,11]$.

The remarkable adaptability of bacteria makes them inhabit and survive in almost any environment, often even in the most extreme. Every new generation of microbes is able to adapt its genes in response to continuously changing stressful environmental conditions, while humans have the ability to affect this process through excessive chemical stimulation in the environment $[12,13]$.

To-date, only a few studies have explored the role of invertebrates and vertebrates living in their natural ecosystems in the dissemination of Enterobacteriaceae that can contribute to epidemiological monitoring of the environment $[14,15]$. 


\section{OBJECTIVE}

The research objective was to assess the importance of Strix aluco as a reservoir and transmitter in the chosen biocenoses, as well as a potential health threat to workers of the forestry service, nature protection service and ornithologists occupationally exposed to epidemiologically-relevant Enterobacteriaceae strains, the synthesizing extendedspectrum beta-lactamases.

\section{MATERIALS AND METHOD}

Using cloacal swabs, material for microbiological study was collected once from Strix aluco chicks in nest boxes hung at the turn of 2009-2010 within the project of active conservation of birds, commissioned by and with the permission of the Poleski National Park. E type nest boxes were hung which were designed mainly for this bird species and readily occupied by them [16]. Under laboratory conditions, bacteria proliferated on lysogeny broth LB medium (bioMerieux) which was subsequently synchronically transferred on to chromID ESBL medium (bioMerieux) [17] and SS (bioMerieux). After incubation on the selected media, bacterial colonies were selected for further identification and analysis. A whole collection of isolated strains underwent biochemical testing and each strain was identified by the API $20 \mathrm{E}$ commercial kit system (bioMerieux). Their susceptibility to chemotherapeutic agents was established using disc diffusion assay protocol with Mueller-Hinton agar (bioMerieux) and the application of plates. To determine the drug sensitivity of isolates, the following chemotherapeutics were used: ampicillin (AM concentration $10 \mu \mathrm{g} / \mathrm{ml}$ ), streptomycin (S $10 \mathrm{MU}$ ) and gentamicin (GM $10 \mu \mathrm{g} / \mathrm{ml})$. Additionally, tetracycline (TE $30 \mathrm{MU}$ ), nitrofurantoin (FM $300 \mathrm{MU}$ ), chloramphenicol (C $30 \mu \mathrm{g} / \mathrm{ml}$ ) and sulphonamides with trimethoprim (SXT $1.25+23.75 \mu \mathrm{g} / \mathrm{ml}$ ) were applied.

For testing the drug susceptibility of Enterobacteriaceae strain pool selected on the chromID ESBL medium, chemotherapeutics belonging to penicillins (ampicillin AM $10 \mu \mathrm{g} / \mathrm{ml}$ ), $\mathrm{n}$ fourth-generation cephalosporins(cefepime CPM 30), cefamicins(cefoxitin FOX 30), monobactams(aztreonam ATM 30), carbapenems(imipenem IMI 10) and clavams (timentin TIM 85) were used. After incubation, the test results were interpreted according to the disc manufacturer's instructions.

\section{RESULTS AND DISCUSSION}

Among the isolates recovered from the birds from all the research locations, 14 taxa were identified within the Enterobacteriaceae. The decreasing impact of anthropopressure allowed the ordering of the research locations as follows: II, I and III, IV and V. The majority of taxa were identified at location II in Załucze - agrocenotic, while 7 taxa in location IV (far from the typical agrocenosis) and 7 in location V (a forest research site).

Citrobacter braaki was isolated from the birds from all the research locations, while Buttiauxella agrestis, Escherichia coli,Enterobacter cloacae and Proteus vulgaris - were isolated from 4 research sites (Tab. 1). Bacteria producing extended- spectrum beta-lactamases falling within 6 taxa were selected using chromID ESBL medium. The strains showing this capability were recovered from birds at each research location, but there were different taxa, a maximum of 3 , at locations I and II (Tab. 1).

Table 1. Enterobacteriaceae taxa isolated from Strix aluco from 5 research sites, including ESBL synthesizing strains

\begin{tabular}{|c|c|c|c|c|c|c|}
\hline Bacterial taxon & Letter abbreviation & $\mathrm{LI}$ & LII & LIII & LIV & LV \\
\hline Aerobacter hydrophila & Ah & + & - & + & - & - \\
\hline Buttiauxella agrestis & $\mathrm{Ba}$ & - & + & + & + & + \\
\hline Citrobacter braakii & $\mathrm{Cb}$ & + & $+\mathrm{E}$ & $+\mathrm{E}$ & + & $+\mathrm{E}$ \\
\hline Citrobacter freundii & Cf & $+\mathrm{E}$ & - & - & $+\mathrm{E}$ & + \\
\hline Citrobacter koseri/amalonaticus & $\mathrm{Ck} / \mathrm{a}$ & - & - & + & - & - \\
\hline Citrobacter youngae & Cy & - & + & - & + & + \\
\hline Escherichia coli & Ec & $+\mathrm{E}$ & $+\mathrm{E}$ & + & + & - \\
\hline Enterobacter cloacae & $\mathrm{Ecl}$ & + & + & + & + & - \\
\hline Enterobacter sacazakii & Es & - & + & - & - & - \\
\hline Hafnia alvei & $\mathrm{Ha}$ & + & - & + & - & + \\
\hline Klebsiella pneumoniae & $\mathrm{Kp}$ & - & $+\mathrm{E}$ & - & - & - \\
\hline Proteus mirabilis & $\mathrm{Pm}$ & + & + & - & - & + \\
\hline Proteus vulgaris & Pv & $+\mathrm{E}$ & + & - & $+\mathrm{E}$ & + \\
\hline Salmonella arizonae & Sa & - & - & $+\mathrm{E}$ & - & - \\
\hline
\end{tabular}

$\mathrm{E}$ - there were isolated ESBL synthesizing strains, i.e. extended-spectrum $\beta$-lactamases

Location:

LI Channel of the Wola Wereszczyńska colony

LII Załucze Museum

LIII Wojciechów

LIV Wólka Wytycka

LV Lejno

Analyzing the Enterobacteriaceae pool obtained from all the birds, there was found to be an increasing drug sensitivity of strains to chosen chemotherapeutics, along with a decreasing anthropopressure degree at the research locations under study. The highest efficacy preventing growth of the studied isolates was demonstrated by sulphonamides, nitrofurantoin and tetracycline (Tab. 2).

Currently, one of the mechanisms of drug resistance in bacteria, the most substantial regarding clinical and epidemiological aspect, proved to be beta-lactamases with an extended spectrum of action $[18,19,20]$. Because of the expansiveness and anthropogenic stimulation of mutation, it is not surprising that strains capable of producing ESBL were isolated from wild animals. The most commonly found and described in literature ESBL-synthesizing strains are strains of Escherichia coli and Klebsiella pneumoniae [21, 22]. Presently, these strains are identified in numerous species of Enterobacteriaceaerods [23,24], which is consistent with the obtained results.

Strains producing an extended-spectrum beta-lactamases degrade penicillin, including ampicillin, while under in vitro conditions partially-degraded cefepime which is a fourthgeneration cephalosporin. The studied isolates exhibited sensitivity or intermediate sensitivity to cephotoxin, imipenem and timentin, whereas most of them degraded aztreonam (Tab.3). These results conform with the mechanism of extended-spectrum beta-lactamase action towards the selected chemotherapeutics. It is challenging to draw any conclusion on habitat differentiability on the grounds of a profile of resistance to beta-lactam drugs; however, it is a very 
Table 2. Sensitivity to chemotherapeutics (\%) of Enterobacteriaceae strains ( $\mathrm{n}=40$ isolated from Strix aluco from five research locations

\begin{tabular}{lccccccc}
\hline Location & & $\mathrm{C}$ & $\mathrm{T}$ & $\mathrm{SXT}$ & $\mathrm{S}$ & $\mathrm{FM}$ & $\mathrm{AM}$ \\
\hline LI & $\mathrm{S}$ & 45 & 70 & 100 & 0 & 60 & 25 \\
\hline & $\mathrm{I}$ & 55 & 30 & 0 & 60 & 25 & 50 \\
\hline & $\mathrm{R}$ & 0 & 0 & 0 & 40 & 15 & 25 \\
\hline LII & $\mathrm{S}$ & 25 & 50 & 90 & 0 & 0 & 0 \\
\hline & $\mathrm{I}$ & 70 & 50 & 10 & 50 & 50 & 50 \\
\hline & $\mathrm{R}$ & 5 & 0 & 0 & 50 & 50 & 50 \\
\hline LIII & $\mathrm{S}$ & 55 & 50 & 100 & 0 & 50 & 15 \\
\hline & $\mathrm{I}$ & 45 & 50 & 0 & 60 & 25 & 60 \\
\hline & $\mathrm{R}$ & 0 & 0 & 0 & 40 & 25 & 25 \\
\hline LIV & $\mathrm{S}$ & 50 & 65 & 100 & 0 & 60 & 40 \\
\hline & $\mathrm{I}$ & 40 & 35 & 0 & 75 & 30 & 60 \\
\hline & $\mathrm{R}$ & 0 & 0 & 0 & 25 & 10 & 0 \\
\hline LV & $\mathrm{S}$ & 70 & 80 & 100 & 0 & 70 & 80 \\
\hline & $\mathrm{I}$ & 30 & 20 & 0 & 75 & 30 & 20 \\
\hline & $\mathrm{R}$ & 0 & 0 & 0 & 25 & 0 & 0
\end{tabular}

$\mathrm{S}$ - sensitivity; I - intermediate sensitivity; $\mathrm{R}$ - resistance; C - Chloramphenicol (30); $\mathrm{T}$ - Tetracycline (30); SXT - Trimethopr. + Sulfmethox (1.25+23.75); S - Streptomycyn (10); FM - Nitrofurantoin (300); AM - Ampicillin (10). Number in brackets shows chemotherapeutics content in disc

Location:

LI Channel of the Wola Wereszczyńska colony

LII Załucze Museum

LIII Wojciechów

LIV Wólka Wytycka

LV Lejno

Table 3. Sensitivity to $\beta$-lactam chemotherapeutics (\%) of Enterobacteriaceae strains synthesizing ES $\beta \mathrm{L}(\mathrm{n}=20)$ isolated from Strix aluco from 5 research locations

\begin{tabular}{cccccccc}
\hline Location & & AM & CPM & FOX & ATM & IMI & TIM \\
\hline LI & S & 0 & 10 & 45 & 0 & 50 & 80 \\
\hline & I & 25 & 60 & 55 & 25 & 50 & 20 \\
\hline LII & R & 75 & 30 & 0 & 75 & 0 & 0 \\
\hline & S & 0 & 5 & 70 & 5 & 40 & 60 \\
\hline & I & 25 & 20 & 30 & 35 & 60 & 40 \\
\hline & $\mathrm{R}$ & 75 & 75 & 0 & 60 & 0 & 0 \\
\hline & $\mathrm{S}$ & 0 & 0 & 50 & 0 & 70 & 65 \\
\hline LIV & $\mathrm{I}$ & 50 & 35 & 50 & 40 & 30 & 35 \\
\hline & $\mathrm{R}$ & 50 & 65 & 0 & 60 & 0 & 0 \\
\hline & $\mathrm{S}$ & 0 & 0 & 60 & 5 & 75 & 65 \\
\hline LV & $\mathrm{R}$ & 60 & 60 & 0 & 65 & 0 & 0 \\
\hline & $\mathrm{S}$ & 0 & 0 & 80 & 10 & 80 & 80 \\
\hline & $\mathrm{I}$ & 50 & 20 & 20 & 30 & 20 & 20 \\
\hline & $\mathrm{R}$ & 50 & 80 & 0 & 60 & 0 & 0
\end{tabular}

S - sensitivity; I - intermediate sensitivity; R - resistance; AM - Ampicillin (10); CPM Cefepim (30); FOX - Cefoxitin (30); ATM - Aztreonam (30); IMI - Imipenem (10); TIM - Timentin (85). Number in brackets shows chemotherapeutics content in disc.

Location:

LI Channel of the Wola Wereszczyńska colony

LII Załucze Museum

LIII Wojciechów

LIV Wólka Wytycka

LV Lejno

significant fact that wild animals harbour Enterobacteriaceae strains able to synthesize enzymes degrading this type of substances.
Apparently, this type of microbiological study of the environment concerns only preliminary phenotypic characteristics of bacterial strains; therefore, it is recommended to further pursue genetic identification of isolate phylogenesis. Earlier studies have indicated the possibility of Enterobacteriaceae transmission by land snails in their natural habitats [25]. Notably, the obtained research results have proved the possibility exists of signalling epidemiological threats by Strigiformes order birds that occupy habitats to various anthropopressure degrees.

\section{CONCLUSIONS}

The Strix aluco taxon under study is a reservoir and can be a vector transmitting Enterobacteriaceae bacteria which are potential pathogens for human and animals. The bacterial isolates were obtained from birds from the research locations of a varied anthropopressure degree.

Most bacterial strain species recovered from the gastrointestinal tract of the bird were of clinical and epidemiological importance, as contributing to nosocomial or community acquired infections. Identification of multiresistant isolates in the analyzed samples indicates an environmental regulation of resistance induction.

The application of chromID ESBL (bioMérieux) as a bacterial growth medium confirmed the presence of strains capable of generating ESBL resistance mechanisms, and allowed for preliminary identification of bacterial strains. Dissemination of strains producing extended-spectrum betalactamases can also occur between different animal species in the environment, due to the localization of genes encoding their synthesis on conjugal plasmids.

An epidemiological role of bacterial strains isolated from the bird gastrointestinal tract is associated with the pathogenic properties of these microorganisms and defence mechanisms of humans and animals exposed to them. The obtained results of the microbiological evaluation indicate the importance of the studies on the transfer of bacterial strains of potential clinical relevance in natural ecosystems.

\section{REFERENCES}

1. Cios Sz, Grzywaczewski G. Importance of selected factors influencing the size of tawny owl Strix aluco territories in the forests of Lublin region. Sylwan 2013; 157(5): 348-357.

2. Wiącek J, Polak M, Grzywaczewski G. The Role of Forest Age, Habitat Quality, Food Resources and Weather Conditions for the Tawny Owl Strix aluco Populations. Polish J of Environ Stud. 2010; 19(5): 1039-1043.

3. Cramp S. (editor). Handbook of the Birds of Europe the Middle East and North Africa Vol 4. Oxford, New York, Oxford University Press, 1985. 4. Nowakowski G, Kochańska-Dziurowicz A, Widala E. Leptospirosis tick - Lyme disease. Przegląd Lekarski. 2000; 57(7-8): 424-426 (in Polish).

5. Romankow J, Kusiak W.Risk of tick- borne diseases in forestry workers. Nowiny Lek. 2004; 73(6): 454-458 (in Polish).

6. Dutkiewicz J, Śpiewak R, Jabłoński L, Szymańska J. Occupational biological risk factors - classification exposed occupational groups, measurement, prevention. Lublin, Ad punctum. 2007; (in Polish).

7. Cherubin CE, Eng RHK, Smith SM. Cephalosporin therapy for salmonellosis-Questions of efficacy and cross resistance with ampicillin. Arch Intern Med. 1986; 146: 2149-2152.

8. Karlowsky JA, Jones ME, Thornsberry C, Friedland IR, Sahm DF. Trends in Antimicrobial Susceptibilities among Enterobacteriaceae Isolated from Hospitalized Patients in the United States from 1998 to 2001,Antimicrob Agents Chemother. 2003; 47(5): 1681-1688. 
9. Gupta R, Rauf SJ, Singh S, Smith J, Agraharkar ML. Sepsis in a renal transplant recipient due to Citrobacter braakii. Southern Medical Journal. 2003; 96(8): 796-798.

10. Bush K, Jacoby GA, Medeiros AA. A functional classification scheme for $\beta$-lactamases and its correlation with molecular structure. Antimicrob Agents Chemother. 1995; 39: 1211-1233.

11. Livermore DM. $\beta$-lactamases in laboratory and clinical resistance. Clin Microbiol Rev. 1995; 8: 557-584.

12. Leclerc H, Mossel DAA, Edberg SC, Struijk CB. Advances in the Bacteriology of the Coliform Group: Their Suitability as Markers of Microbial Water Safety. Annu Rev Microbiol. 2001; 55: 201-34.

13. Pepperell C, Kus JV, Gardam MA, Humar A, Burrows LL. Low-Virulence Citrobacter Species Encode Resistance to Multiple Antimicrobials; 2002; 46(11): 3555-3560.

14. Bhatt BD, Zuckerman MJ, Foland JA, Disseminated Salmonella arizonae infection associated with rattlesnake meat ingestion. Am J Gastroenterol. 1989; 84: 433-435.

15. Chiodini RJ, Sundberg JP. Salmonellosis in reptiles: A review. Am J Epidemiol. 1981; 113: 494-499.

16. Gryz J, Krauze-Gryz D.The use of nest boxes by owls Strix aluco in central Poland. Studia i Materiały CEPL. 2011; 27: 120-125 (in Polish).

17. Stefaniuk E, Herda M, Kozińska A, Hryniewicz W. Chromogenic substrate chromID ESBL bioMérieux in monitoring hospital infections. Wyd bioMérieux Polska. 2008 (in Polish).
18. Kotra LP, Mobashery S. $\beta$-Laktam antibiotics, $\beta$-lactamases and bacterial resistance. Bull. Inst. Pasteur. 1998; 96: 139-150.

19. Bradford PA. Extended-spectrum $\beta$-lactamases in the 21 st century: characterization, epidemiology, and detection of this important resistance threat. Clin Microbiol Rev. 2001; 14: 933-95.

20. Essack SY. The Development of $\beta$-Laktam Antibiotics in Response to the Evolution of $\beta$-Lactamases. Pharmaceutical Research. 2001; 18(10): 1391-1399.

21. Jakoby GL, Sutton L. $\beta$-lactamases and $\beta$-lactam resistance in Escherichia coli. Antimicrob Agents Chemother. 1985; 28: 703-705.

22. Chen ST, Clowes RC. Variations between the nucleotide sequence of Tn1, Tn2, and Tn 3 and expression of $\beta$-lactamase in Pseudomonas aeruginosa and Escherichia coli. J Bacteriol. 1987; 169: 913-916.

23. Shah AA, Hasan F, Ahmed S, Hameed A. Characteristics, epidemiology and clinical importance of emerging strains of Gram-negative bacilli producing extended-spectrum $\beta$-lactamases. Research in Microbiology. 2004; 155: 409-421.

24. Thomson KS, Smith Moland E. Version 2000: the new $\beta$-lactamases of Gram-negative bacteria at the dawn of the new millennium. Microbes and Infection. 2000; 2: 1225-1235.

25. Kowalczyk-Pecka D, Puchalski A. Potential interaction between the Cepaea nemoralis wild snail and Citrobacter spp. bacteria. Vet Med. 2008; 64(6): 786-790. 